\title{
Atividade de três drogas antivirais sobre os herpesvírus bovino tipos 1, 2 e 5 em cultivo celular ${ }^{1}$
}

\author{
Renata Dezengrini' ${ }^{2}$, Sara C. da Silva ${ }^{2}$, Marcelo Weiss ${ }^{2,3}$, Luiz C. Kreutz ${ }^{4}$, \\ Rudi Weiblen ${ }^{5}$ e Eduardo F. Flores ${ }^{5^{\star}}$
}

\begin{abstract}
Dezengrini R., Silva S.C., Weiss M., Kreutz L.C., Weiblen R. \& Flores E.F. 2010. [Activity of three antiviral drugs against bovine herpesviruses 1,2 and 5 in cell culture.] Atividade de três drogas antivirais sobre os herpesvírus bovino tipos 1, 2 e 5 em cultivo celular. Pesquisa Veterinária Brasileira 30(10):855-860. Setor de Virologia, Departamento de Medicina Veterinária Preventiva, Centro de Ciências Rurais, Universidade Federal de Santa Maria, Av. Roraima 1000, Camobi, Santa Maria, RS 97105-900, Brazil. E-mail: eduardofurtadoflores@gmail.com

The activity of three anti-herpetic drugs (Acyclovir [ACV], Gancyclovir [GCV] and Foscarnet [PFA]) was tested against bovine herpesvirus 1 (BoHV-1), 2 (BoHV-2) and 5 (BoHV-5) in vitro using the plaque reduction assay. Different drug concentrations were tested against one hundred $50 \%$ tissue culture infectious dose $\left(\mathrm{TCID}_{50}\right)$ of the respective viruses. Drug concentrations lower than $200 \mu \mathrm{g} / \mathrm{mL}$ resulted in viability rates of more than $80 \%$ for MDBK and Hep2 cells in the MTT test (3-(4,5-Dimethylthiazol-2-yl)-2,5-diphenyltetrazolium bromide). The selectivity index (IS) of the drugs was calculated dividing the concentration of the drug that is cytotoxic for $50 \%$ of the cells $\left(\mathrm{CC}_{50}\right)$ by the concentration of the drug that was effective in reducing by $50 \%$ the number of viral plaques $\left(E C_{50}\right)$ for the three herpesviruses. Thus, ACV was shown to be moderately active against BoHV-1 (EC $: 112.9 \mu \mathrm{g} / \mathrm{mL}$; IS: 4.5$)$, BoHV-2 (EC ${ }_{50}: 114.2 \mu \mathrm{g} / \mathrm{mL}$; IS: 4.5$)$ and BoHV-5 (EC $\left.{ }_{50}: 96.9 \mu \mathrm{g} / \mathrm{mL} ; \mathrm{IS}: 5.3\right)$. GCV was effective against BoHV-2 (EC ${ }_{50}: 33.5 \mu \mathrm{g} / \mathrm{mL}$; IS: 16.6), moderately effective against BoHV-5 (EC ${ }_{50}$ : $123.2 \mu \mathrm{g} / \mathrm{mL}$; IS: 4.5 ) and poorly active against BoHV-1 (EC $\left.{ }_{50}: 335.8 \mu \mathrm{g} / \mathrm{mL} ; \mathrm{IS}: 1.7\right)$. PFA exhibited the highest antiviral activity, being the only drug that, at concentration of $100 \mu \mathrm{g} / \mathrm{mL}$, completely inhibited plaque formation by all three viruses. PFA was the most effective in vitro against BoHV-1 (EC ${ }_{50}: 29.5 \mu \mathrm{g} / \mathrm{mL}$; IS: 42.2$)$, BoHV-2 $\left(\mathrm{EC}_{50}: 45.2 \mu \mathrm{g} / \mathrm{mL}\right.$; IS: 27.6$)$ and BoHV-5 (EC ${ }_{50}: 7.8 \mu \mathrm{g} / \mathrm{mL}$; IS: 160.6). Thus, the results indicate that PFA is a promising candidate for experimental therapeutic testing in vivo against bovine herpesviruses.
\end{abstract}

INDEX TERMS: Antivirals, BoHV-1, BoHV-2, BoHV-5, Foscarnet, Gancyclovir, Acyclovir.

RESUMO.- A atividade de três fármacos antivirais (Aciclovir [ACV], Ganciclovir [GCV] e Foscarnet [PFA]) foi testada in vitro frente aos herpesvírus bovino tipos 1 (BoHV-1), 2 (BoHV-2) e 5 (BoHV-5). Para isso, utilizou-se o teste de

\footnotetext{
${ }^{1}$ Recebido em 3 de fevereiro de 2010.

Aceito para publicação em 21 de julho de 2010.

2 Programa de Pós-Graduação em Medicina Veterinária (PPGMV), Universidade Federal de Santa Maria (UFSM), Santa Maria, RS, Brasil.

3 Plum Island Animal Disease Center, USDA/ARS/NAA, P.O. Box 848, Greenport, NY 11944, USA.

4. Universidade de Passo Fundo, Campus I, Bairro São José. BR 285 Km 171, Cx. Postal 611, Passo Fundo, RS 99001-970, Brasil.

${ }^{5}$ Setor de Virologia, Departamento de Medicina Veterinária Preventiva, e Departamento de Microbiologia e Parasitologia, Centro de Ciências Rurais, UFSM, Av, Roraima 1000, Camobi, Santa Maria, RS 97105900, Brasil. E-mail: eduardofurtadoflores@gmail.com
}

redução de placas virais em cultivo celular, testando-se diferentes concentrações dos fármacos frente a 100 doses infectantes para $50 \%$ dos cultivos celulares $\left(\mathrm{DICC}_{50}\right)$ dos respectivos vírus. Pelo teste de MTT (3-(4,5-Dimethylthiazol2-yl)-2,5-diphenyltetrazolium bromide), verificou-se que concentrações inferiores a $200 \mu \mathrm{g} / \mathrm{mL}$ dos três antivirais resultaram em índices de viabilidade de células MDBK e Hep2 superiores a $80 \%$. Com base na concentração citotóxica para $50 \%$ das células $\left(\mathrm{CC}_{50}\right)$ e na concentração dos fármacos efetiva para inibir em $50 \%$ o número de placas virais $\left(E_{50}\right)$, calculou-se o índice de seletividade (IS) dos antivirais para os três herpesvírus. Assim, o ACV demonstrou ser moderadamente ativo frente ao BoHV-1 $\left(\mathrm{EC}_{50}: 112,9 \mu \mathrm{g} / \mathrm{mL}\right.$ e IS: 4,5$)$, ao BoHV-2 (EC ${ }_{50}: 114,2 \mu \mathrm{g} / \mathrm{mL}$ e IS: 4,5 ) e BoHV5 (EC ${ }_{50}: 96,9 \mu \mathrm{g} / \mathrm{mL}$ e IS: 5,3$)$. O GCV apresentou atividade 
moderada frente ao BoHV-2 (EC $\mathrm{EC}_{50}: 33,5 \mu \mathrm{g} / \mathrm{mL}$ e IS: 16,6$)$ e, em menor grau, contra o BoHV-5 (EC $\mathrm{E}_{50}: 123,2 \mu \mathrm{g} / \mathrm{mL}$ e IS: $4,5)$, sendo ineficaz frente ao BoHV-1 (EC ${ }_{50}: 335,8 \mu \mathrm{g} / \mathrm{mLe}$ IS: 1,7). O PFA apresentou atividade antiviral mais pronunciada, sendo o único fármaco que, na concentração de 100 $\mathrm{gg} /$ $\mathrm{mL}$, inibiu completamente a produção de placas pelos três vírus testados. O PFA foi o mais efetivo in vitro frente ao BoHV-1 (EC 50 : 29,5 $\mu \mathrm{g} / \mathrm{mL}$ e IS: 42,2), ao BoHV-2 (EC 5 : $45,2 \mu \mathrm{g} / \mathrm{mL}$ e IS: 27,6$)$ e ao BoHV-5 (EC $50: 7,8 \mu \mathrm{g} / \mathrm{mL}$ e IS: $160,6)$. Portanto, os resultados obtidos indicam que o PFA pode se constituir em um candidato para terapia experimental de infecções pelos herpesvírus de bovinos in vivo.

TERMOS DE INDEXAÇÃO: Antivirais, BoHV-1, BoHV-2, BoHV5, Foscarnet, Ganciclovir, Aciclovir.

\section{INTRODUÇÃO}

Os herpesvírus bovino tipos 1 (BoHV-1), 2 (BoHV-2) e 5 (BoHV-5) são vírus DNA de cadeia dupla linear, que possuem um capsídeo de simetria icosaédrica e envelope lipoprotéico, classificados na família Herpesviridae, subfamília Alphaherpesvirinae. Esses vírus estabelecem e reativam infecções latentes em seus hospedeiros, propriedade que permite a sua manutenção na natureza (Rock et al. 1992, Roizman 1992). O BoHV-1 e 5 pertencem ao gênero Varicellovirus, e o BoHV-2 é classificado no gênero Simplexvirus (Roizman 1992). O BoHV-1 é associado com doença respiratória (rinotraqueíte infecciosa bovina, IBR), conjuntivite, vulvovaginite/balanopostite pustular infecciosa (IPV/IBP), infertilidade transitória e abortos (Roizman 1992, Kahrs 2001). O BoHV-2 é associado à mamilite herpética bovina (BHM), doença vesicular e erosiva do úbere e tetos, que acomete principalmente vacas leiteiras de primeira cria (Kahrs 2001). O BoHV-5 é o agente da meningoencefalite herpética, doença geralmente fatal em bovinos jovens, e que ocorre com frequência na Argentina e no Brasil (Carrillo et al. 1983, Rissi et al. 2006).

Historicamente, os herpesvírus humanos têm sido alvo para o desenvolvimento e teste de fármacos antivirais. $O$ Aciclovir (ACV) e o Ganciclovir (GCV) são análogos de nucleosídeos, cujas moléculas consistem de uma guanina associada a uma molécula similar a um acúcar acíclico (Coen \& Richman 2007). Ambos são fosforilados por quinases virais a monofosfato (timidina quinase - TK e a fosfotransferase UL97, respectivamente), e em seguida, por quinases celulares a trifosfato (Coen \& Richman 2007). A ação desses antivirais é mediada pela sua incorporação na cadeia nascente de DNA viral, impedindo que a DNA polimerase dos herpesvírus complete seu ciclo catalítico (Whitley \& Roizman 2001, Coen \& Richman 2007). O Foscarnet (PFA) é um análogo sintético do pirofosfato que, uma vez incorporado na cadeia de DNA pela polimerase, impede que essa enzima complete o seu ciclo catalítico (Eriksson et al. 1982, Coen \& Richman 2007).

Estudos de atividade antiviral com herpesvírus de animais têm sido ocasionalmente conduzidos (Schwers et al. 1980, Thiry et al. 1983, Maggs \& Clarke 2004, Marley et al.
2006, Meulen et al. 2006, Garré et al. 2007). Assim, foi demonstrado que o ACV é pouco ativo frente ao BoHV-1 (Thiry et al. 1983) e ao herpesvírus felino 1 - FeHV-1 (Maggs \& Clarke 2004, Meulen et al. 2006). Foi demonstrado também que o ACV é 10 vezes menos efetivo do que o GCV frente ao herpesvírus equino 1 (EqHV-1) in vitro (Garré et al. 2007). Outros estudos demonstraram que o GCV inibe a replicação do FeHV-1 em células de linhagem felina (Maggs \& Clarke 2004, Meulen et al. 2006). A eficácia deste antiviral frente ao FeHV-1, juntamente com a Idoxuridina, foi superior à de outros quatro fármacos (Maggs \& Clarke 2004). Dentre seis antivirais testados frente ao EqHV-1, o GCV foi o mais ativo in vitro, sendo considerado o fármaco de escoIha para testes de eficácia em equinos (Garré et al. 2007).

Garré et al. (2007) observaram que a redução do número de placas produzidas pelo EqHV-1 in vitro pelo PFA varia de acordo com a cepa ou isolado. Esse antiviral foi ainda associado com redução do número e tamanho de placas produzidas pelo BoHV-1 in vitro, sugerindo-se que o fármaco possa ser utilizado in vivo (Schwers et al. 1980). A atividade do PFA contra o BoHV-1 também foi testada em embriões bovinos in vitro, nos quais inibiu a replicação viral na concentração de $400 \mu \mathrm{g} / \mathrm{mL}$ (Marley et al. 2006).

A terapia antiviral é uma prática comum em humanos, porém pouco utilizada em infecções por herpesvírus em animais. A maioria dos estudos, conduzidos in vitro, investigaram a eficiência de antivirais comerciais frente ao FeHV-1 (Maggs \& Clarke 2004, Meulen et al. 2006; Hussein et al. 2008a) e, com menor frequência, frente ao BoHV-1 (Schwers et al. 1980, Thiry et al. 1983, Marley et al. 2006). Apesar de alguns estudos demonstrarem atividade antiviral de fármacos de uso humano contra herpesvírus bovino in vitro, pouco se sabe sobre a eficácia de antivirais frente a esses vírus, não existindo formulações disponíveis para tratamento de infecções herpéticas nesta espécie. Provavelmente, isso se deve ao custo elevado do tratamento, principalmente para grandes animais. Neste sentido, coeIhos têm sido utilizados como modelo para estudos de patogenia do BoHV-1 e BoHV-5 (Flores et al. 2009) e cobaias para estudos com o BoHV-2 (Torres et al. 2009). Para estas espécies, existe a possibilidade de se realizar estudos com antivirais, associados ou não a outros fármacos. Assim, o conhecimento acerca da atividade in vitro de antivirais contra esses agentes pode permitir a realização de estudos de patogenia e terapêutica adicionais frente ao BoHV-1, BoHV-2 e BoHV-5, bem como, em situações especiais, para o tratamento de animais de alto valor zootécnico (Dezengrini et al. 2009, Flores et al. 2009). Por esta razão, inicialmente investigou-se a atividade antiviral in vitro de três fármacos utilizados para o tratamento de infecções herpéticas humanas (ACV, GCV e PFA) frente ao BoHV-1, BoHV-2 e BoHV-5.

\section{MATERIAL E MÉTODOS}

$A$ atividade in vitro do Aciclovir (ACV), Ganciclovir (GCV) e Foscarnet (PFA) foi testada frente ao BoHV-1, BoHV-2 e BoHV5 em células de cultivo, pelo teste de redução do número de 
placas. Inicialmente, utilizando-se doses crescentes do Aciclovir (ACV), Ganciclovir (GCV) e Foscarnet (PFA), investigou-se a toxicidade desses fármacos para células MDBK e Hep-2, determinando-se a dose tóxica para $50 \%$ das células $\left(\mathrm{EC}_{50}\right)$. Posteriormente, a atividade antiviral de cada fármaco foi testada, in vitro, frente ao BoHV-1, BoHV-2 e BoHV-5 em células de cultivo, pelo teste de redução do número de placas.

\section{Células e vírus}

Células de linhagem de rim bovino MDBK (ATCC, CCL22) e da linhagem Hep-2 (ATCC, CCL-23), cultivadas em meio essencial mínimo (MEM; Invitrogen Brasil LTDA, São Paulo, $\mathrm{SP}$, Brasil) e suplementadas com $5 \%$ de soro equino (SE) ou soro fetal bovino (SFB; Cultilab Materiais para Cultura de CéIulas Ltda, Campinas, SP, Brasil), respectivamente, $100 \mathrm{U} /$ $\mathrm{mL}$ de penicilina e $100 \mu \mathrm{g} / \mathrm{mL}$ de estreptomicina (Nutricell nutrientes celulares LTDA, Campinas, SP, Brasil) foram utilizadas para amplificação e quantificação dos vírus, ensaios de placa e testes de citotoxicidade. Células MDBK foram usadas para os herpesvírus bovinos bem como para o BVDV; células Hep-2 foram usadas para o HSV-1. As cepas de BoHV-5 SV507/99 (Delhon et al. 2003), BoHV-2 (cedida pelo Dr. Fernando Osório, University of Nebraska, Lincoln, Nebraska, EUA), e BoHV-1 SV-56/90 (Weiblen et al. 1992) foram testadas quanto a sua sensibilidade aos três fármacos. A cepa Singer do BVDV (Dr. Ruben Donis, University of Nebraska, Lincoln, Nebraska, EUA) e a cepa KOS do HSV-1 (Dr. Paulo Michel Roehe, Universidade Federal do Rio Grande do Sul, Porto Alegre, RS, Brasil) foram utilizadas como controles negativos e positivos, respectivamente, da sensibilidade viral aos fármacos.

\section{Fármacos}

Três fármacos antivirais comerciais indicados para o tratamento de infecções por herpesvírus humanos foram selecionados para os testes in vitro: o ACV (peso molecular PM - 225; Galena, Campinas, SP, Brasil), GCV (PM 255.2; Brasvit, Rio de Janeiro, RJ, Brasil) e PFA (PM 300.1; Sigma-Aldrich, St Louis, $\mathrm{MO}, \mathrm{EUA})$. Os fármacos foram diluídos na concentração de $1 \mathrm{mg} / \mathrm{mL}$ em solução salina (ACV); solução salina com $0,5 \%$ de dimetilsulfóxido (DMSO) (GCV), ou em água ultrapura (PFA) imediatamente antes do uso.

\section{Teste de viabilidade celular}

$\mathrm{O}$ teste de MTT (3-(4,5-Dimethylthiazol-2-yl)-2,5-diphenyltetrazolium bromide) foi utilizado para investigar a toxicidade dos três antivirais para as células de cultivo. Células MDBK ou Hep-2 $\left(1,6 \times 10^{5}\right.$ células/cavidade de placas de poliestireno com 96 cavidades) foram incubadas por $24 \mathrm{~h}$ a $37^{\circ} \mathrm{C}$ em estufa de $\mathrm{CO}_{2}$ a $5 \%$ com diluições seriadas dos três antivirais $(1,10,100$, 200 e $500 \mu \mathrm{g} / \mathrm{mL}$ ), ou mantidas como controles, em triplicata, e submetidas ao teste de MTT adaptado de Garré et al. (2007). Após $24 \mathrm{~h}$ de incubação com o fármaco, removeu-se o sobrenadante e adicionou-se $50 \mu \mathrm{L}$ de MTT $(1 \mathrm{mg} / \mathrm{mL}$ em MEM) por cavidade, e as células foram incubadas (MDBK por $2 \mathrm{~h}$ e Hep2 por $4 \mathrm{~h}$ ) a $37^{\circ} \mathrm{C}$ em estufa de $\mathrm{CO}_{2}$ a $5 \%$. Em seguida, removeu-se o MTT e adicionou-se $100 \mu \mathrm{L}$ de DMSO por cavidade, incubando-se por $15 \mathrm{~min}$ a $37^{\circ} \mathrm{C}$ sob agitação constante. $\mathrm{O}$ sobrenadante foi passado para uma nova placa de 96 cavidades e a absorbância (em densidade óptica - OD) foi medida a um comprimento de onda de 550nm em um leitor de ELISA. Foram conduzidos dois testes independentes, e a viabilidade de células foi calculada para cada concentração de antiviral testada pela seguinte fórmula: \% células viáveis = média $O D$ (antiviral) x 100/média OD (controles).

As porcentagens de células viáveis para cada concentração do fármaco foram utilizadas para o cálculo da concentração citotóxica para $50 \%$ das células $\left(\mathrm{CC}_{50}\right)$, por análise de regressão linear. No teste de MTT, considerou-se tóxica a concentração de antiviral em que a viabilidade das células foi inferior a $80 \%$, em comparação com os controles (Garré et al. 2007).

\section{Atividade antiviral in vitro}

O teste de redução do número de placas virais (Meulen et al. 2006, Garré et al. 2007) foi utilizado para investigação da atividade antiviral in vitro dos três fármacos frente ao BoHV-1, BoHV-2 e BoHV-5. No teste, utilizou-se o HSV-1 e o BVDV Singer como controles positivo e negativo, respectivamente. Para isso, foram utilizadas células MDBK ou Hep 2 (HSV-1) cultivadas em placas de poliestireno de seis cavidades (aproximadamente $2 \times 10^{6}$ células/cavidade). Previamente ao ensaio, três cavidades contendo células receberam $1 \mathrm{~mL}$ de MEM com a concentração do antiviral a ser testada $(0,1 ; 1 ; 10 ; 25 ; 75$ e $100 \mu \mathrm{g} / \mathrm{mL}$ ) e três cavidades foram mantidas como controles, e incubadas por $1 \mathrm{~h}$ a $37^{\circ} \mathrm{C}$ em estufa de $\mathrm{CO}_{2}$ a $5 \%$. Em seguida, o sobrenadante foi removido e os tapetes celulares foram lavados, adicionando-se $1 \mathrm{~mL}$ de inóculo contendo aproximadamente 100 DICC $_{50}$ (doses infectantes para $50 \%$ dos cultivos celulares) do respectivo vírus, por cavidade. Após $2 \mathrm{~h}$ de adsorção, o inóculo foi removido e os tapetes celulares foram recobertos com $2 \mathrm{~mL}$ de MEM contendo $5 \%$ de SE ou SFB, $0,95 \%$ de carboximetilcelulose ${ }^{f}$ e a respectiva concentração de antiviral em $\mu \mathrm{g} / \mathrm{mL}$. Após $48 \mathrm{~h}$ de incubação a $37^{\circ} \mathrm{C} \mathrm{em}$ estufa de $\mathrm{CO}_{2}$ a $5 \%$, foi realizada a contagem do número de placas virais nas cavidades, com o auxílio de uma lâmina milimetrada adaptada à superfície inferior da placa. Foram realizados pelo menos dois testes independentes, em triplicata, com cada concentração dos antivirais.

A inibição da replicação viral foi calculada a partir da fórmula: \% inibição da replicação viral = 1-(número médio de placas virais nas cavidades com antiviral/ número médio de placas virais nas cavidades sem antiviral) $\times 100$. A concentração de cada fármaco efetiva para inibir em $50 \%$ o número de placas virais $\left(\mathrm{EC}_{50}\right)$ e o índice de seletividade (IS) foram calculados por análise de regressão linear, considerando-se a equação da reta adequada quando o valor de $\mathrm{R}^{2}$ foi igual ou superior a 0,9. O IS é a relação entre a $\mathrm{CC}_{50}$ do fármaco (obtido pelo $\mathrm{MTT}$ ) e a $\mathrm{EC}_{50}$. Este valor é utilizado para estimar a segurança de medicamentos, tanto para a utilização em humanos, quanto para animais e, quanto maior o valor deste (acima de 1), maior a diferença entre a dose de antiviral que reduz em 50\% a replicação viral $\left(E_{50}\right)$ e a dose citotóxica $\left(C_{50}\right)$. Portanto maior a segurança do fármaco para uso nas respectivas células (Coen \& Richman 2007).

\section{RESULTADOS}

Citotoxicidade dos antivirais para os cultivos celulares

No teste de MTT, verificou-se que todas as concentrações dos três antivirais testadas, exceto a de $500 \mu \mathrm{g} / \mathrm{mL}$, resultaram em viabilidade celular acima de $80 \%$ (dados não apresentados). Assim, optou-se por utilizar concentrações de até $200 \mu \mathrm{g} / \mathrm{mL}$ nos testes com os três fármacos em células MDBK e Hep-2. Os valores de concentra- 
ção citotóxica para $50 \%$ das células $\left(\mathrm{CC}_{50}\right)$ dos fármacos estão apresentados no Quadro 1.

Quadro 1. Atividade do Aciclovir (ACV), Ganciclovir (GCV) e Foscarnet (PFA) sobre a replicação in vitro dos herpesvírus bovino tipo 1 (BoHV-1), tipo 2 (BoHV-2) e tipo 5 (BoHV-5)

\begin{tabular}{|c|c|c|c|c|c|c|}
\hline \multirow{3}{*}{$\begin{array}{c}\text { Herpesvírus } \\
\text { de } \\
\text { bovinos }\end{array}$} & \multicolumn{6}{|c|}{ Fármaco } \\
\hline & \multicolumn{2}{|c|}{ Aciclovir } & \multicolumn{2}{|c|}{ Ganciclovir } & \multicolumn{2}{|c|}{ Foscarnet } \\
\hline & $\mathrm{EC}_{50}{ }^{\mathrm{a}}$ & $I^{b}$ & $\mathrm{EC}_{50}$ & IS & $\mathrm{EC}_{50}$ & IS \\
\hline BoHV-1 & $112,9^{c}$ & 4,5 & 335,8 & 1,7 & 29,5 & 42,2 \\
\hline BoHV-2 & 114,2 & 4,5 & 33,5 & 16,6 & 45,2 & 27,6 \\
\hline BoHV-5 & 96,9 & 5,3 & 123,2 & 4,5 & 7,8 & 160,6 \\
\hline $\mathrm{CC}_{50}{ }^{\mathrm{d}}$ & \multicolumn{2}{|c|}{$508,3 / 130,3$} & \multicolumn{2}{|c|}{$556,2 / 111,4$} & \multicolumn{2}{|c|}{$1.245,1 / 4.869,9$} \\
\hline
\end{tabular}

a $\mathrm{EC}_{50}$ : concentração de cada fármaco efetiva para inibir em $50 \%$ o número de placas virais, em $\mu \mathrm{g} / \mathrm{mL}$.

b IS: índice de seletividade; relação entre a $\mathrm{CC}_{50}$ e a $\mathrm{EC}_{50}$.

c Os valores se referem à concentração do antiviral em $\mu \mathrm{g} / \mathrm{mL}$.

${ }^{d} \mathrm{CC}_{50}$ : concentração do fármaco em $\mu \mathrm{g} / \mathrm{mL}$ citotóxica para $50 \%$ das células MDBK/Hep 2.

\section{Atividade antiviral in vitro do ACV, GCV e PFA frente aos herpesvírus de bovinos}

A concentração de antiviral que inibiu $50 \%$ da replicação dos vírus $\left(E_{50}\right)$ e o índice de seletividade (IS) do ACV, GCV e PFA frente a 100 DICC $_{50}$ do BoHV-1, BoHV-2 e BoHV5 estão apresentados no Quadro 1. Esses valores foram calculados a partir das porcentagens de redução do número de placas, que são apresentados na Figura 1. O PFA inibiu completamente a formação de placas pelos três vírus testados na concentração de $100 \mu \mathrm{g} / \mathrm{mL}$. Frente ao HSV-1,
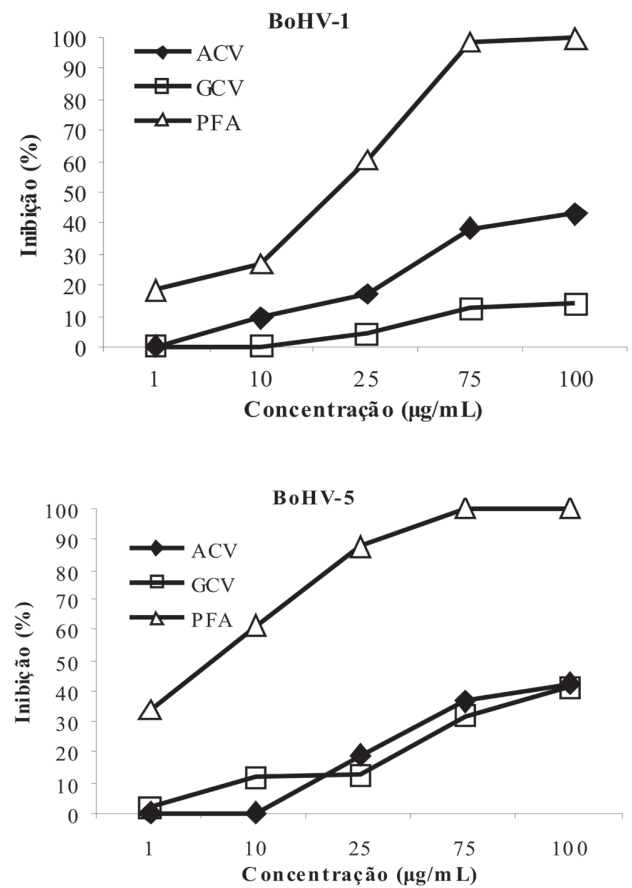

Fig.1. Porcentagem de inibição da replicação viral (redução no número de placas virais) in vitro pelo Aciclovir, Ganciclovir e Foscarnet frente aos herpesvírus bovino tipos 1 (BoHV1), 2 (BoHV-2), 5 (BoHV-5) e herpes simplex tipo 1 (HSV-1). Os dados representam a média de dois experimentos independentes realizados em triplicata. mero de placas (dados não apresentados).

\section{DISCUSSÃO} (GCV) e Foscarnet (PFA). da (Thiry et al. 1983, Glotov et al. 2004).
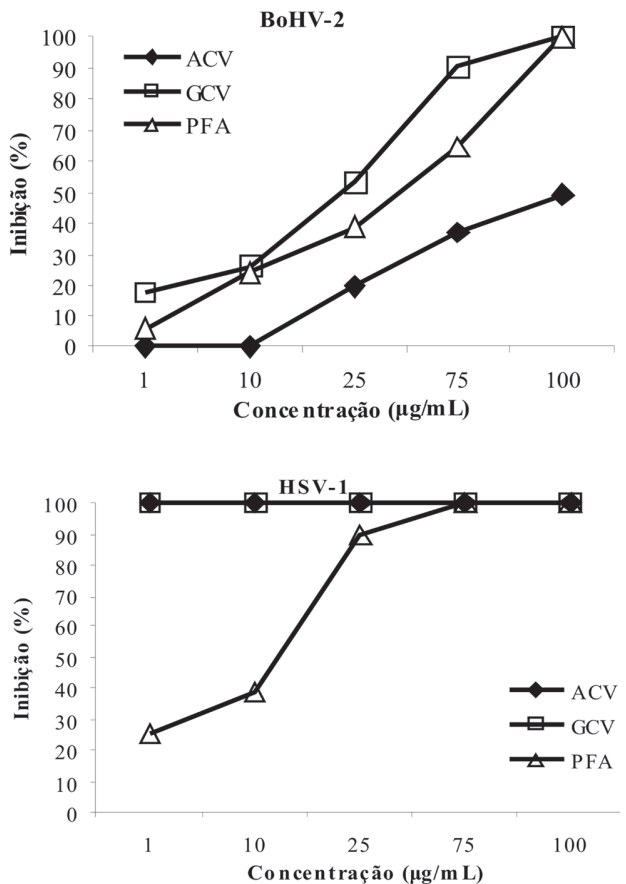

todas as concentrações testadas do ACV e GCV, e as concentrações de 75 e 100ìg/mL do PFA, inibiram completamente a formação de placas virais, demonstrando a atividade desses fármacos nos testes realizados. Nenhuma das concentrações dos três antivirais testadas inibiu a replicação do BVDV, demonstrando a especificidade da atividade anti-herpética desses fármacos no teste de redução do nú-

Dentre os antivirais com eficácia anti-herpética comprovada, foram selecionados três fármacos disponíveis comercialmente, que são utilizados para o tratamento de infecções herpéticas humanas: Aciclovir (ACV), Ganciclovir

No teste de redução do número de placas, o ACV apresentou-se pouco a moderadamente ativo (Fig.1), com uma $\mathrm{EC}_{50}$ comparativamente elevada e IS baixo para os três herpesvírus testados (Quadro 1). Estes achados são compatíveis aos relatos de atividade in vitro do ACV frente a outros herpesvírus animais, como o FeHV-1 e EqHV-1, contra os quais a $\mathrm{EC}_{50}$ desse antiviral é 11 e 20 vezes maior que a do GCV, respectivamente (Meulen et al. 2006, Garré et al. 2007). Estudos anteriores realizados in vitro também demonstraram atividade controversa do ACV frente ao BoHV-1, sendo necessárias concentrações elevadas do fármaco para que a atividade antiviral fosse evidencia-

Enzimas de outros herpesvírus não fosforilam o ACV de forma eficiente como a TK do HSV e VZV (Coen \& 
Richman 2007), o que poderia explicar a baixa atividade deste antiviral contra os herpesvírus animais. Estudos têm demonstrado que a TK de herpesvírus animais possuem alta similaridade de nucleotídeos com a TK do HSV-1, porém a especificidade por substratos e as propriedades cinéticas dessa enzima frente a fármacos são diferentes entre as espécies de herpesvírus humanos e animais (Solaroli et al. 2008). Foi demonstrado ainda que a baixa eficiência do ACV frente ao FeHV-1 é devida à fosforilação pouco eficiente pela TK desse vírus, uma vez que, na presença da TK do HSV-1, a DNA polimerase do FeHV-1 apresenta alta afinidade pelo ACV (Hussein et al. 2008a). Portanto, a baixa ativação do ACV pelo FeHV-1 é atribuída a diferenças da sequência de aminoácidos e estruturais na TK, que resultam na ligação desse fármaco à TK em um sítio diferente para fosforilar o ACV. Quando esses dois resíduos são substituídos na TK do FeHV-1 para mimetizar a ligação do ACV à TK do HSV-1, a ativação desse antiviral aumenta em 3 vezes (Hussein et al. 2008b).

O GCV foi comparativamente eficaz na redução do número de placas do BoHV-2, apresentando um baixo valor de $\mathrm{EC}_{50}$ e elevado IS (Quadro 1). O BoHV-2, dentre os três vírus testados, é o que possui maiores semelhanças genéticas com o HSV-1 (Ehlers et al. 1999). Contra esse vírus, o GCV também apresentou-se eficaz, inibindo completamente a sua replicação em todas as concentrações testadas (Fig.1). A atividade do GCV frente ao HSV-1 foi demonstrada anteriormente (Duan et al. 2008). Porém, foram necessárias concentrações maiores desse fármaco para observar-se efeito antiviral frente ao BoHV-5, e frente ao BoHV-1 o GCV foi ineficaz. O GCV é considerado o antiviral de escolha para inibir a replicação ou limitar a disseminação do FeHV-1 in vitro, juntamente com o Cidofovir e o PMEDAP; e seguido pelo PMEDAP e ACV para o EqHV1 (Meulen et al. 2006, Garré et al. 2007).

O PFA foi o fármaco que apresentou os melhores resultados frente ao BoHV-1, BoHV-2 e BoHV-5, sendo o único que, na concentração de $100 \mu \mathrm{g} / \mathrm{mL}$, inibiu completamente a formação de placas pelos três herpesvírus de bovinos testados (Fig. 1). Além disso, os valores de $\mathrm{EC}_{50}$ foram inferiores aos do ACV e GCV para o BoHV-1 e BoHV5 , apresentando IS superiores para os três vírus (Quadro 1). A atividade antiviral do PFA já havia sido demonstrada frente ao BoHV-1, em células do cumulus co-cultivadas com embriões bovinos. Os títulos do vírus foram reduzidos em quatro logaritmos na concentração de $200 \mu \mathrm{g} / \mathrm{mL}$, e a replicação viral foi inibida completamente frente a $400 \mu \mathrm{g} /$ $\mathrm{mL}$ (Marley et al. 2006). Por outro lado, o PFA apresenta atividade intermediária frente ao FeHV-1 in vitro, se comparado a outros fármacos como o GCV e o Cidofovir. Testes com o EqHV-1 demonstraram que o PFA reduz o número de placas virais, porém essa ação varia de acordo com o isolado viral, apresentando, por isso, valor limitado para o tratamento de infecções por esse vírus (Meulen et al. 2006, Garré et al. 2007).

Para o BoHV-2, o GCV apresentou um valor de $\mathrm{EC}_{50}$ mais baixo que o PFA. O valor de IS, no entanto, foi supe- rior para o PFA, indicando que este seria mais seguro para estudos in vivo com este vírus. Além disso, o GCV somente pode ser utilizado por infusão intravenosa, o que dificultaria a formulação de pomadas de uso tópico na glândula mamária de fêmeas bovinas. Embora a mamilite herpética bovina seja uma doença auto-limitante, possui importância em rebanhos leiteiros, pois pode produzir redução na produção de leite e predispor a infecções bacterianas, responsáveis por mastites (Wellenberg et al. 2002). Pela semelhança com o HSV-1 e o HSV-2, acredita-se que fármacos disponíveis para o tratamento das infecções herpéticas humanas possam se constituir em alternativas para o tratamento das lesões vesiculares e erosivas produzidas pelo BoHV-2 (Field et al. 2006). Esse vírus também tem sido indicado como modelo para estudos com o HSV-1, pela sua semelhança genética e antigênica (Ehlers et al. 1999).

A aplicabilidade de fármacos antivirais para o tratamento de infecções herpéticas em bovinos é passível de questionamento, sobretudo pelo seu alto custo. Não obstante, o conhecimento da atividade antiviral de fármacos contra o BoHV-1 e BoHV-5 pode ser aplicado em estudos de patogenia e terapêutica antiviral em modelos animais, especialmente camundongos e coelhos. Da mesma forma, o tratamento da mamilite herpética pelo BoHV-2 em rebanhos de alta produção e severamente afetados pode se constituir em alternativa economicamente justificável. Assim, o conhecimento da atividade antiviral de drogas disponíveis, frente aos herpesvírus animais, pode contribuir para o delineamento de terapias experimentais e/ou para o tratamento de algumas dessas enfermidades em situações especiais.

Agradecimentos.- À colega do Setor de Virologia Marciele Ribas Pilau, pelo auxílio na realização dos ensaios de citotoxicidade pelo MTT.

\section{REFERÊNCIAS}

Carrillo B.J., Pospischil A. \& Dahme E. 1983. Pathology of a bovine viral necrotizing encephalitis in Argentina. Zbl. Veterinärmed. B 30(3):161-168.

Clercq E.D. 2001. Molecular targets for antiviral agents. J. Pharmacol. Exp. Therapeut. 297(1):1-10.

Coen D.M. \& Richman D.D. 2007. Antiviral agents, p.447-485. In: Knipe D.M. \& Howley P.M. (Eds), Fields Virology. $5^{\text {th }}$ ed. Williams and Wilkins, Philadelphia.

Delhon G.A., Moraes M.P., Lu Z., Afonso C.L., Flores E.F., Weiblen R., Kutish G.F. \& Rock D.L. 2003. Genome of bovine herpesvirus 5. J. Virol. 77(19):10339-10347.

Dezengrini R., Weiss M., Torres F.D., Oliveira M.S., Furian A.F., Mello C.F., Weiblen R. \& Flores E.F. 2008. Bovine herpesvirus 5 induces an overproduction of nitric oxide in the brain of rabbits that correlates with virus dissemination and precedes the development of neurological signs. J. Neurovirol. 15(2):153-163.

Duan R., de Vries R.D., Osterhaus A.D., Remeijer L. \& Verjans G.M. 2008. Acyclovir-resistant corneal HSV-1 isolates from patients with herpetic keratitis. J. Infect. Dis. 198:659-663.

Ehlers B., Goltz M., Ejercito M.P., Dasika G.K. \& Letchworth G.J. 1999. Bovine herpesvirus type 2 is closely related to the primate alphaherpesviruses. Virus Genes 19(3):197-203.

Eriksson B., Oberg B. \& Wahren B. 1982. Pyrophosphate analogs 
as inhibitors of DNA polymerases of cytomegalovirus, herpes simplex virus and cellular origin. Biochimica et Biophysica Acta 696(2):115-123.

Flores E.F., Weiblen R., Vogel F.S.F., Dezengrini R., Almeida S.R., Spilki F.R. \& Roehe P.M. 2009. Neuropatogênese experimental da infecção pelo herpesvírus bovino tipo 5 em coelhos. Pesq. Vet. Bras. 29(1):1-16.

Garré B., van der Meulen K., Nugent J., Neytsd J., Croubelsb S., De Backerband P. \& Nauwynck H. 2007. In vitro susceptibility of six isolates of equine herpesvirus 1 to acyclovir, ganciclovir, cidofovir, adefovir, PMEDAP and foscarnet. Vet. Microbiol. 122(1/2):43-51.

Field H.J., Biswas S. \& Mohammad I.T. 2006. Herpesvirus latency and therapy - from a veterinary perspective. Antiviral Res. 71(2/ 3):127-133.

Glotov A.G., Glotova T.I., Sergeev A.A. \& Sergeev A.N. 2004. Study of antiviral activity of different drugs against bovine herpes virus and pestivirus. Antibiotiki i Khimioterapiia 49(6):06-09.

Hussein I.T.M., Menashy R.V. \& Field H.J. 2008a. Penciclovir is a potent inhibitor of feline herpesvirus- 1 with susceptibility determined at the level of virus-encoded thymidine kinase. Antiviral Res. 78(3):268-274.

Hussein I.T.M., Miguel R.N., Tiley L.S. \& Field H.J. 2008b. Substrate specificity and molecular modelling of the feline herpesvirus-1 thymidine kinase. Archs Virol. 153:495-505.

Kahrs R.F. 2001. Viral Diseases of Cattle. $2^{\text {nd }}$ ed. lowa State University Press, Ames.

Maggs D.J. \& Clarke H.E. 2004. In vitro efficacy of ganciclovir, cidofovir, penciclovir, foscarnet, idoxuridine and acyclovir against feline herpesvirus type-1. Am. J. Vet. Res. 65(4):399-403.

Marley M.S., Givens M.D., Stringfellow D.A., Galik P.K. \& Riddell K.P. 2006. Effect of phosphonoformic acid in the development of bovine embryos in vitro. Vet. Therapeut. 7(2):156-166.

Meulen K.V.D., Garré B., Croubels S. \& Nauwynck H. 2006. In vitro comparison of antiviral drugs against feline herpesvirus 1. BMC Vet. Res. 2(13):1-7.

Naesens L. \& Clercq E.D. 2001. Recent developments in herpesvirus therapy. Herpes 8(1):12-16.
Rissi D.R., Oliveira F.N., Rech R.R., Pierezan F., Lemos R.A.A. \& Barros C.S.L. 2006. Epidemiology, clinical signs and distribution of the encephalic lesions in cattle affected by meningoencephalitis caused by bovine herpesvirus-5. Pesq. Vet. Bras. 26(2):123-132.

Rock D.L., Lokensgard J., Lewis T. \& Kutish G. 1992. Characterization of dexamethasone-induced reactivation of latent bovine herpesvirus 1. J. Virol. 66(4):2484-2490.

Roizman B., Desrosiers R.C., Fleckenstein B., Lopez C., Minson A.C. \& Studdert M.J. 1992. The family Herpesviridae: An update. Archs Virol. 123( 3/4):432-445.

Schwers A., Pastoret P.P., Vindevogel H., Leroy P., Aguilar-Setien A. \& Godart M. 1980. Comparison of the effect of trisodium phosphonoformate on the mean plaque size of pseudorabies virus, infectious bovine rhinotraqueitis virus and pigeon herpesvirus. J. Comp. Pathol. 90(4):625-633.

Solaroli N., Johansson M., Persoonsb L., Balzarinib J. \& Karlsson A. 2008. Substrate specificity of feline and canine herpesvirus thymidine kinase. Antiviral Res. 79:128-132.

Thiry E., Vindevogel H., Leroy P., Pastoret P.P., Schwers A., Brochier B., Anciaux Y. \& Hoyois P. 1983. In vivo and in vitro effect of acyclovir on pseudorabies virus, infectious bovine rhinotracheitis virus and pigeon herpesvirus. Annales Recherches Vétérinaries 14(3):233-245.

Torres F.D., Cargnelutti J.F., Masuda E.K., Weiblen R. \& Flores E.F. 2009. Acute and latent infection by bovine herpesvirus type 2 in a guinea pig model. Microbial Pathogenesis. 89:161-166.

Weiblen R., Kreutz L.C., Canabarro T.F., Schuch L.F. \& Rebelatto M.C. 1992. Isolation of bovine herpesvirus 1 from preputial swabs and semen of bulls with balanoposthitis. J. Vet. Diagn. Invest. 4(3):341-343.

Wellenberg G.J., van der Poel W.H.M. \& Van Oirschot J.T. 2002.Viral infections and bovine mastitis: A review. Vet. Microbiol. 88(1):27-45.

Whitley R.J. \& Roizman B. 2001. Herpes simplex virus infections. Lancet 357(9257):1513-1518.

Yoshida M., Yamada M., Tsukazaki T., Chatterjee S., Lakeman F.D., Nii S. \& Whitley R.J. 1998. Comparison of antiviral compounds against human herpesvirus 6 and 7. Antiviral Res. 40(1/2):73-84. 